\title{
COLORIMETRIC HYDROGEN SENSORS
}

\author{
${ }^{1}$ Anna ZABELINA, ${ }^{1,2}$ Elena MILIUTINA, 1,2Olga GUSELNIKOVA, ${ }^{1}$ Denis ZABELIN, \\ ${ }^{1}$ Vaclav ŠVORČíK, ${ }^{1,2}$ Oleksiy LYUTAKOV
}

${ }^{1}$ VŠCHT - University of Chemistry and Technology, Prague, Czech Republic, EU, lyutakoo@vscht.cz

${ }^{2}$ Tomsk Polytechnic University, Research School of Chemistry and Applied Biomedical Sciences, Tomsk, Russian Federation

https://doi.org/10.37904/nanocon.2020.3708

\begin{abstract}
The area of "green" energy carriers utilization is rapidly developing in the world today. Renewable hydrogen has promising potential as an ecologically safe energy carrier. However, production, storage, transportation and utilization of hydrogen possess certain risks due to the high likelihood of ignition. In this paper, we have demonstrated the design and realization of the colorimetric hydrogen sensor in different liquids. A proposed colorimetric sensor is based on corel-shell Au@Pd nanoparticles, additionally grafted by metal-organic framework IRMOF-20 layer, responsible for hydrogen entrapping. The combination of localized surface plasmon, high affinity of the palladium surface in hydrogen sorption and selectivity of IRMOF-20 towards this gas leads to apparent color change of nanoparticles suspension in hydrogen presence. The proposed approach is favored by high sensitivity, ease of use, low detection limit, and fast response time.
\end{abstract}

Keywords: Colorimetric hydrogen sensor, hydrogen detection, IRMOF-20, core-shell nanoparticles, goldpalladium nanoparticles, surface plasmon resonance

\section{INTRODUCTION}

Under the terms of the Paris Agreement, sustainable energy technological development is an important part of the fight against climate change. After this decision was taken, the demand for "green" energy sources continues to grow [1]. In this regard, renewable hydrogen has promising potential as a green energy carrier [2]. However, the production, storage and utilization of hydrogen is associated with certain risks due to the increased likelihood of inflammation [3-7].

Colorimetric gas sensors may be the best solution to the problems associated with determining the presence of hydrogen in air. In particular, colorimetric sensors based on the principle of localized surface plasmon resonances of silver or gold nanoparticles have a particularly high potential. These sensors change colour in the presence of targeted compounds under room conditions, which is useful in everyday life. Colorimetric sensors can also be made compact and without the presence of electronic components $[8,9]$.

Metal-organic frameworks (MOFs) can improve sensor selectivity and sensitivity through the introduction of additional functionality and surface specificity. MOF is a well-known class of porous materials, the main purpose of which is the capture of gas molecules, including hydrogen molecules (IRMOF-20) [10-19].

\section{EXPERIMENTAL}

\subsection{Materials}

Deionized water (EMD MILLIPORE), thieno[3,2-b]thiophene-2,5-dicarboxylic acid ( $\geq 99.0 \%)$, zinc nitrate $(99.999 \%)$, dimethylformamide ( $\geq 99 \%), \mathrm{N}, \mathrm{N}-$ Diethylformamide ( $\geq 99 \%)$, acetonitrile (HPLC Plus, $\geq 99.9 \%) . \%$ ), 
methanol (analytical standard), dimethyl sulfoxide ( $\geq 99 \%)$, chloroform (analytical standard) dichloromethane (99.8\%), hydrochloric acid, trisodium citrate, gold(III) chloride solution, palladium(II) chloride were ordered from Sigma-Aldrich and used without additional purification. 4-carboxybenzenediazonium tosylate (ADT-COOH) was prepared according to [20]. Preparation of IRMOF-20-modified surface was carried out according to previous work [21].

\subsection{Sample preparation}

Gold nanoparticles were prepared by the Turkevich method [22]. A seed-mediated growth method was used to prepare bimetallic Au@Pd nanoparticles with an Au core and a Pd shell structure [23]. Au@Pd particles were spontaneously modified by diazonium salt by dipping for 2 hours in a freshly prepared aqueous solution of ADT-COOH (concentration $1 \mathrm{mM}$ ). After the modification, the nanoparticles were centrifugated and washed by water and methanol.

Later, the modified Au@Pd were immersed for some time in the mother liquid IRMOF-20. To clean the pores of IRMOF-20 from the solvent in which the MOF was prepared, nanoparticles with a layer of a metal-organic framework were immersed in dichloromethane for several days. Figure 1 schematically shows the preparation route of Au@Pd with IRMOF-20 layer.

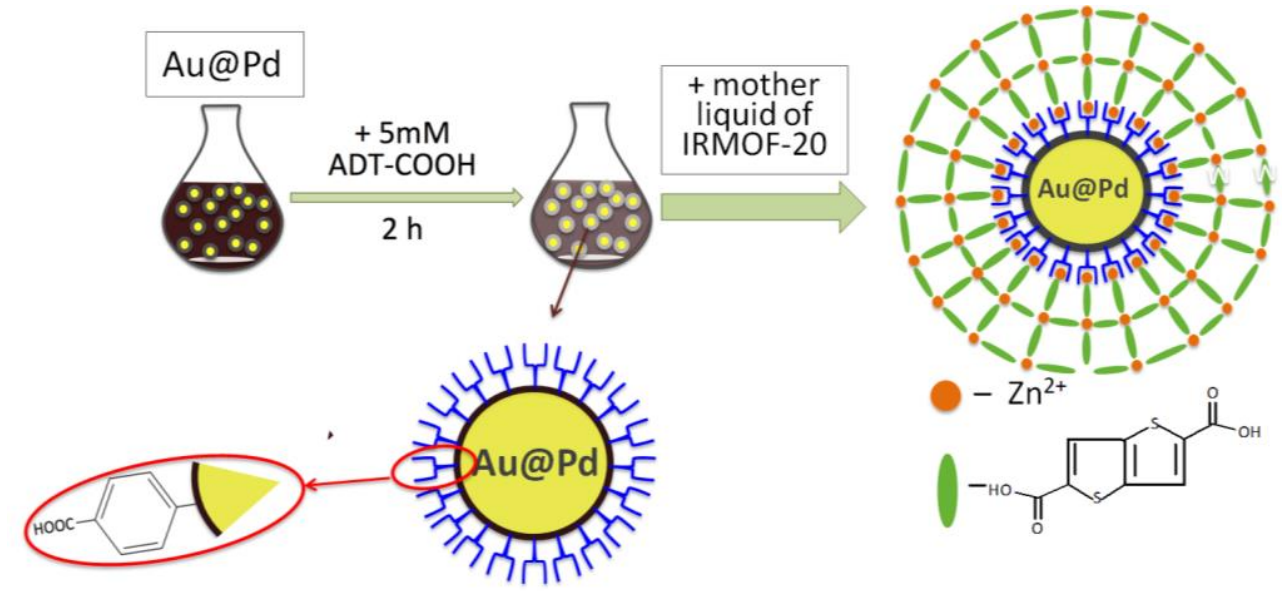

Figure 1 Schematic representation of Au@Pd grafting by -COOH and IRMOF-20

The prepared Au@Pd were dispersed in various solvents of methanol, DMSO, DMF, $\mathrm{CH}_{2} \mathrm{Cl}_{2}, \mathrm{H}_{2} \mathrm{O}$. The hydrogen or carbon dioxide were flown through these solutions for 20 minutes.

\subsection{Measurement Techniques}

Raman spectra were measured using a ProRaman-L (laser power $30 \mathrm{~mW}$ ) spectrometer with an excitation wavelength of $785 \mathrm{~nm}$. Ultraviolet-visible spectroscopy (UV-Vis) spectra were measured using Spectrometer Lambda 25 (Perkin-Elmer) in 300-1100 nm wavelength range.

\section{RESULTS AND DISCUSSION}

Grafting of nanoparticles surface by $-\mathrm{COOH}$ and subsequent IRMOF-20 formation were examined using UVVis (Figure 2A) and SERS (Figure 2B) measurements. UV-Vis spectra (Figure 2A) indicate the presence of absorbance band near $520 \mathrm{~nm}$. After the $-\mathrm{COOH}$ immobilization the band is shifted towards to UV region. Further shifts occur after the formation of IRMOF layer towards to NIR region. As it is evident from the SERS results (Figure 2B), after the grafting procedure, the Raman bands, typical for ADT-COOH and IRMOF-20, become apparent. The obtained results confirm grafting during the both stages of surface modification. 

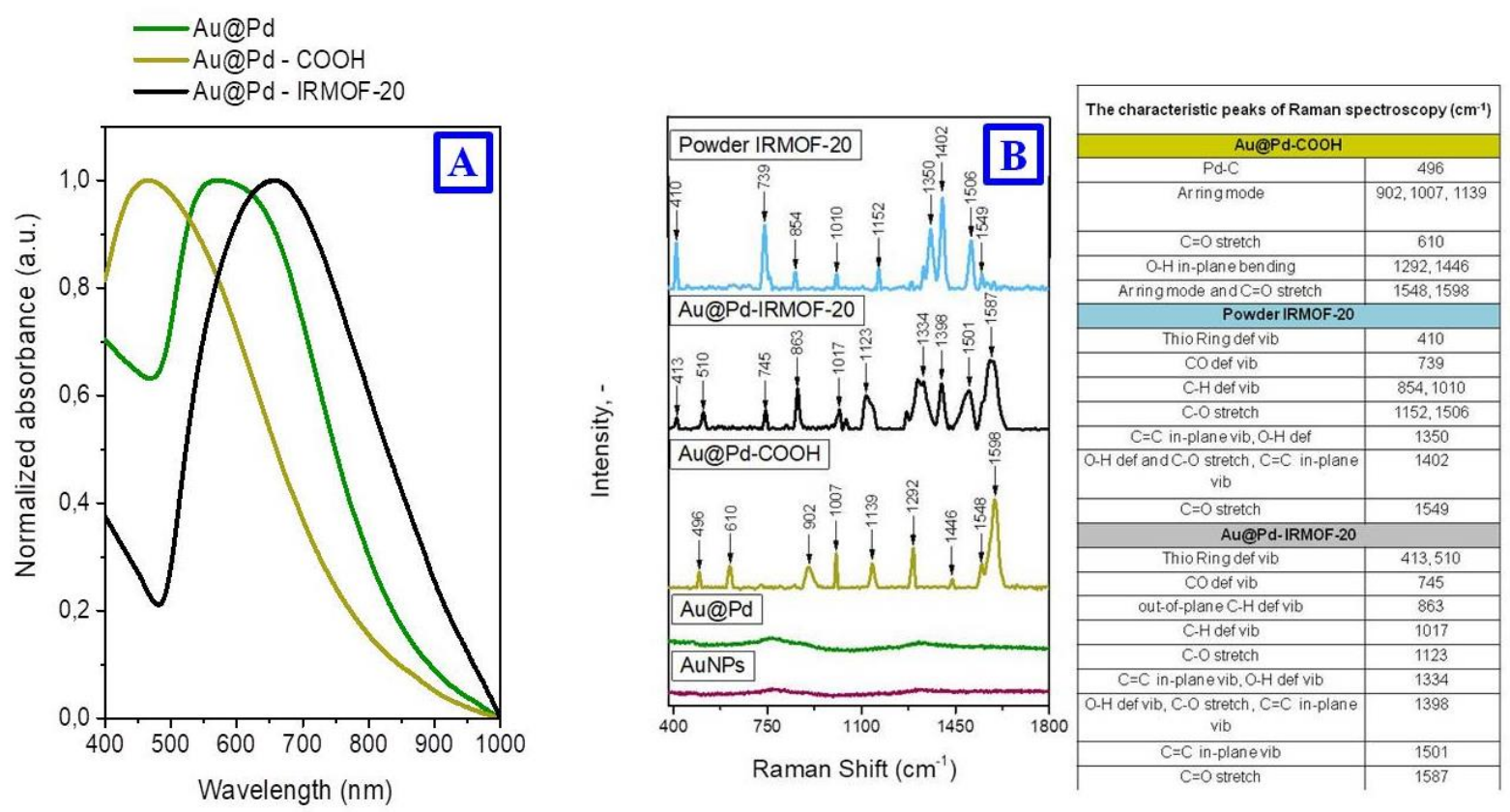

Figure 2 (A) The UV-Vis absorption spectra of: core-shell Au@Pd nanoparticles, Au@Pd grafted by ADT$\mathrm{COOH}$, and Au@Pd decorated with IRMOF20 film, (B) Raman spectra of pristine gold nanoparticles Au@Pd grafted by ADT-COOH, and Au@Pd decorated with IRMOF20 film (right part shows the Raman peak affiliation)
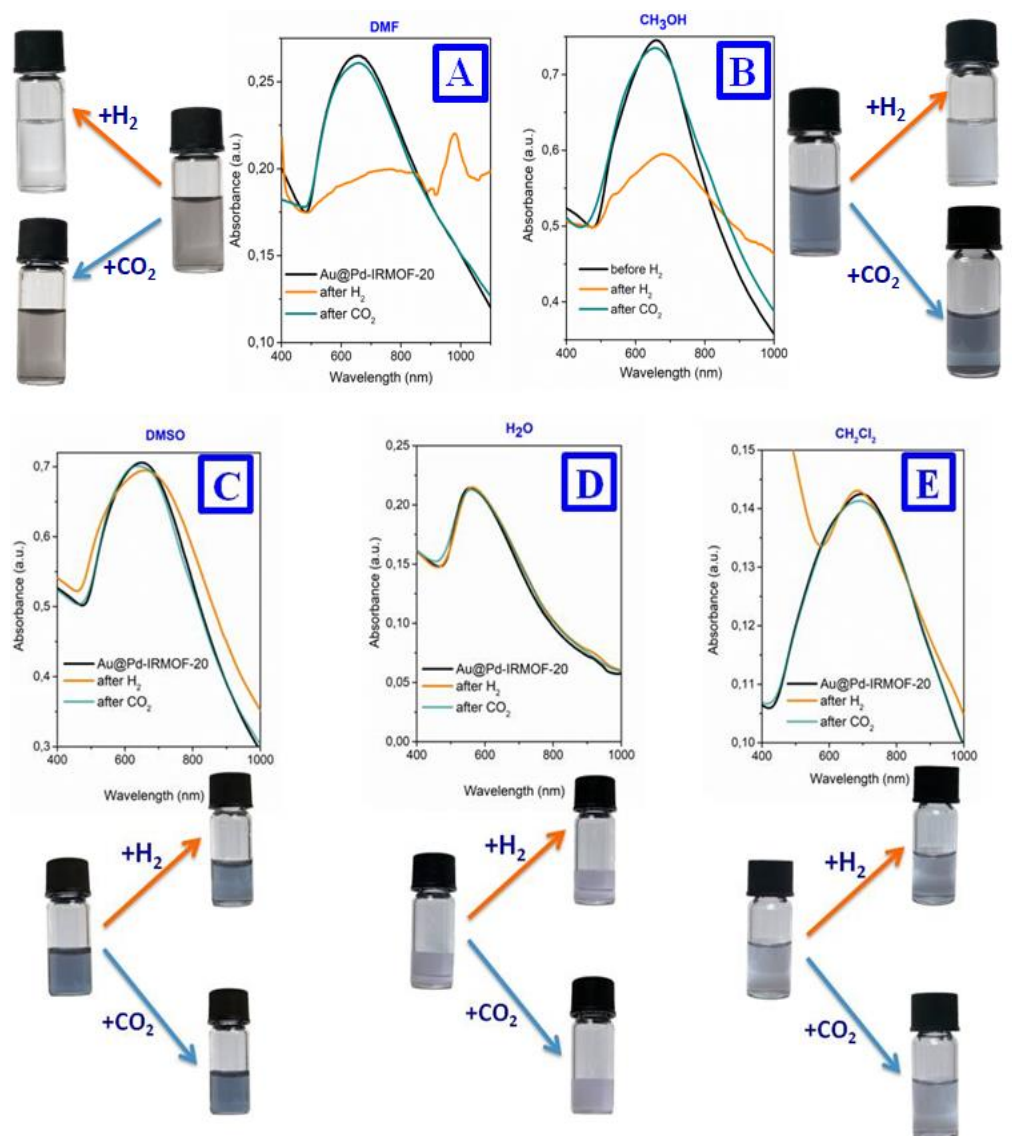

Figure 3 UV-Vis spectra and photos of Au@Pd nanoparticles in different solvents before and after blowing hydrogen and carbon dioxide through: (A) - DMF, (B) $-\mathrm{CH} 3 \mathrm{OH},(\mathrm{C})-\mathrm{DMSO},(\mathrm{D})-\mathrm{H}_{2} \mathrm{O},(\mathrm{E})-\mathrm{CH}_{2} \mathrm{Cl}_{2}$ 
The changes of the IRMOF-20 optical properties due to hydrogen and carbon dioxide entrapping were investigated by UV-Vis absorbance spectra. Figure 3 shows that when carbon dioxide was blown through nanoparticles suspension there were no visible changes in its colour and no displacement of the plasmon absorption peak. However, when hydrogen was bubbled through suspension of nanoparticles in DMF and methanol. The colours were changed. This change was detectable by eyes: In particular, the Figure 3A shows the nanoparticles suspension in DMF and colour changing from gray to transparent. In turn, in methanol suspension the hydrogen presence induces the colour shift from blue to transparent

\section{CONCLUSION}

In this article, we propose a new method for preparation of colorimetric sensors based on bimetallic Au@Pd core-shell nanoparticles with an additional layer of organometallic frameworks for fast and selective detection of hydrogen in organic and inorganic solvents (DMF, $\mathrm{CH}_{3} \mathrm{OH}, \mathrm{DMSO}, \mathrm{CH}_{2} \mathrm{Cl}_{2}$, and water).

The formation of an IRMOF-20 layer on Au@Pd nanoparticles provides possibility of efficient hydrogen detection, through monitoring of the shift of plasmon resonance wavelength position, and, consequently, changes of the suspension colour. The unique properties of IRMOF-20 ensure the sensitivity and selectivity of the developed sensor to hydrogen even in the presence of other gases.

\section{ACKNOWLEDGEMENTS}

This work was supported by under the project Internal Grant Agency UCT №126 882008 and the project Russian Science Foundation (RSF-19-73-00238).

\section{REFERENCES}

[1] HOSTETTLER, S., GADGIL, A., HAZBOUN, E. Sustainable access to energy in the global south. Switzerland: Springer, 2015.

[2] GUSELNIKOVA, O., TRELIN, A., MILIUTINA, E., ELASHNIKOV, R., SAJDL, P., POSTNIKOV, P. S., LYUTAKOV, O. Plasmon-induced water splitting-through flexible hybrid $2 \mathrm{D}$ architecture up to hydrogen from seawater under NIR light. ACS Applied Materials \& Interfaces. 2020, vol. 12, no. 25, pp. 28110-28119

[3] GARCIA, D.A. Analysis of non-economic barriers for the deployment of hydrogen technologies and infrastructures in European countries. International journal of hydrogen energy. 2017, vol. 42. No.10, pp.6435-6447.

[4] BARBIR, F. PEM electrolysis for production of hydrogen from renewable energy sources. Solar energy. 2005, vol. 78, no. 5, pp.661-669.

[5] ABDEL-AAL, H.K., ZOHDY, K.M., KAREEM, M.A. Hydrogen production using sea water electrolysis. The Open Fuel Cells Journal. 2010, vol. 3, no.1.

[6] MORADI, R. AND GROTH, K.M. Hydrogen storage and delivery: Review of the state of the art technologies and risk and reliability analysis. International Journal of Hydrogen Energy. 2019. Vol. 44, no. 23, pp.12254-12269.

[7] ELASHNIKOV, R., ZAHORJANOVA, K., MILIUTINA, E., KOLSKA, Z., CIESLAR, M., SVORCIK, V., LYUTAKOV, $O$. Proton exchange membrane with plasmon-active surface for enhancement of fuel cell effectivity. Nanoscale. 2020, vol. 12, pp. 12068-12075.

[8] RIVERO, P.J., IBAÑEZ, E., GOICOECHEA, J., URRUTIA, A., MATIAS, I.R., ARREGUI, F.J. A self-referenced optical colorimetric sensor based on silver and gold nanoparticles for quantitative determination of hydrogen peroxide. Sensors and Actuators B: Chemical. 2017, vol. 251, pp. 624-631.

[9] CHAUHAN, P.S. AND BHATTACHARYA, S. Hydrogen gas sensing methods, materials, and approach to achieve parts per billion level detection: A review. International Journal of Hydrogen Energy. 2019, vol. 44, no.47, pp. 26076-26099.

[10] MILIUTINA, E., GUSELNIKOVA, O., CHUFISTOVA, S., KOLSKA, Z., ELASHNIKOV, R., BURTSEV, V., LYUTAKOV, O. Fast and All-Optical Hydrogen Sensor Based on Gold-Coated Optical Fiber Functionalized with Metal-Organic Framework Layer. ACS sensors/. 2019, vol. 4, no.12, pp. 3133-3140. 
[11] COLLINS, D.J. and ZHOU, H.C. Hydrogen storage in metal-organic frameworks. Journal of materials chemistry. 2007, vol. 17, no. 30, pp.3154-3160.

[12] WONG-FOY, A.G., MATZGER, A.J. AND YAGHI, O.M. Exceptional H2 saturation uptake in microporous metalorganic frameworks. Journal of the American Chemical Society. 2006, vol. 128, no. 11, pp.3494-3495.

[13] FISCHER, M., HOFFMANN, F., FRÖBA, M. Molecular simulation of hydrogen adsorption in metal-organic frameworks. Colloids and Surfaces A: Physicochemical and Engineering Aspects. 2010, vol. 357, no. 1-3, pp.3542.

[14] BECKNER, M. and DAILLY, A. Adsorption enthalpy calculations of hydrogen adsorption at ambient temperature and pressures exceeding 300 bar. American Journal of Analytical Chemistry. 2013, Vol. 4, no. 10C, pp.8-16.

[15] LIN, X., JIA, J., HUBBERSTEY, P., SCHRÖDER, M., CHAMPNESS, N.R. Hydrogen storage in metal-organic frameworks. CrystEngComm. 2007, vol. 9, no. 6, pp.438-448.

[16] TURNER, M.J., MCKINNON, J.J., JAYATILAKA, D., SPACKMAN, M.A. Visualisation and characterisation of voids in crystalline materials. CrystEngComm. 2011, vol. 13, no. 6, pp.1804-1813.

[17] ZHAO, D., YUAN, D., ZHOU, H.C. The current status of hydrogen storage in metal-organic frameworks. Energy \& Environmental Science. 2008, vol. 1, no. 2, pp.222-235.

[18] BAE, Y.S. AND SNURR, R.Q. Molecular simulations of very high pressure hydrogen storage using metal-organic frameworks. Microporous and mesoporous materials. 2010, vol. 135, no. 1-3, pp.178-186.

[19] RAZAVI, S.A.A., MASOOMI, M.Y., MORSALI, A. Stimuli-Responsive Metal-Organic Framework (MOF) with Chemo-Switchable Properties for Colorimetric Detection of CHCl3. Chemistry-A European Journal. 2017, vol. 23, no. 51 , pp.12559-12564.

[20] FILIMONOV, V.D., TRUSOVA, M., POSTNIKOV, P., KRASNOKUTSKAYA, E.A., LEE, Y.M., HWANG, H.Y., KIM, H. AND CHI, K.W. Unusually stable, versatile, and pure arenediazonium tosylates: their preparation, structures, and synthetic applicability. Organic letters. 2008, vol. 10, no. 18, pp.3961-3964.

[21] ROWSELL, J.L., YAGHI, O.M. Effects of functionalization, catenation, and variation of the metal oxide and organic linking units on the low-pressure hydrogen adsorption properties of metal- organic frameworks. Journal of the American Chemical Society. 2006, vol. 128, no. 4, pp.1304-1315.

[22] KIMLING, J., MAIER, M., OKENVE, B., KOTAIDIS, V., BALLOT, H. AND PLECH, A. Turkevich method for gold nanoparticle synthesis revisited. The Journal of Physical Chemistry B. 2006, vol. 110, no. 32, pp.15700-15707.

[23] ZHENG, Z., XU, H., XU, Z., GE, J. A Monodispersed Spherical Zr-Based Metal-Organic Framework Catalyst, Pt/Au@Pd@ UIO-66, Comprising an Au@ Pd Core-Shell Encapsulated in a UIO-66 Center and Its Highly Selective CO2 Hydrogenation to Produce CO. Small. 2018, vol. 14, no. 5, p.1702812. 